\title{
TEACHER'S ATTITUDE TOWARDS THE INCLUSION OF STUDENTS WITH DISABILITIES IN REGULAR SCHOOLS
}

\author{
Rovena Lika ${ }^{1}$
}

\begin{abstract}
The inclusion of children with disabilities in general schools depends on teachers and pupils. The aim of this study is to evaluate the teachers' role in the inclusion of children with disabilities in general schools. Taking their role into consideration, we will be able to understand factors that influence the positive or negative attitude towards the inclusion of children with disabilities in general classrooms. 146 teachers participated in this study. The instrument used (created by Jeffrey Bailey) for data collection consisted on a self-reporting questionnaire divided into two sections. In the first section, demographic information from teachers is required. In the second section, teachers' attitude towards the inclusion of children with disabilities in general schools is measured. According to the results: Teacher's gender $[\mathrm{t}(144)=0,503, \mathrm{P}=0,616]$ did not affect their attitudes towards the inclusion of children with disabilities in regular schools. Training on inclusive education $[\mathrm{r}=0.75, \mathrm{n}$ $=146$ and $\mathrm{p}=0.001]$ positively affected the attitudes of the teachers. It was concluded that development of trainings for teachers should be focused on because it creates professionals with knowledge of specific techniques.
\end{abstract}

UDC Classification: 377, DOI: http://dx.doi.org/10.12955/cbup.v4.817

Key words: teachers, attitude, role, children with disabilities.

\section{Introduction}

Inclusive education is an international policy that aims to include students with different abilities in regular school programs. School curriculum, teaching methods, sources and organizations should be adapted to allow all students, despite their abilities, to participate successfully in regular classrooms (Mittler, 1995). Moreover, schools should accommodate all children regardless physical, intellectual, social, emotional, linguistic or other conditions (Salamanca Statement, 1994).

Although children with disabilities are different, they all share the same experience of having to overcome barriers of inclusion within school contexts and elsewhere. Enrollment and inclusion of children with disabilities in the preschool system and in the compulsory education afterwards still remains a disturbing problem in Albania. Various factors seem to hinder the inclusion of these children in regular education, such as difficulties in identifying children with disabilities, improper and poor facilities at schools and kindergartens, lack of teachers specialized in working with such children, lack of teaching assistants within classrooms, intolerant attitudes and ignorance in society regarding the rights of these children. Therefore, there is an increasing need for adequate changes and improvements in the educational system and the social setting as well.

According to data from the Directorate of Statistics in the Ministry of Education and Sports, a total of 2,514 students with physical and mental disabilities attend state primary and secondary education (a nine-grade system in Albania), while the number decreases dramatically in high schools with only 342 students.

Other obstacles to an inclusive education include: teachers' attitudes and strict teaching methods, inadequate curricula for disabled children, lack of didactic equipment to meet the students' special needs, physically unreachable school facilities, parents' exclusion and the lack of an inclusive education policy being implemented in schools.

\section{Methodology}

This is a quantitative study.

Sample

The procedure used to collect data on teachers' attitudes towards inclusion of children with disabilities in regular school programs was as follows:

Six 9-year schools in Tirana were deliberately chosen, mainly because of the access granted for the completion of questionnaires. Following the selection of the six schools, information about the exact

\footnotetext{
${ }^{1}$ Rovena Lika, European University of Tirana, Tirana, Albania, rovena.lika@uet.edu.al
} 
number of teachers working in these schools was obtained from the Regional Education Directorate of Tirana.

Table 1: The study population

\begin{tabular}{|c|c|c|}
\hline Schools & Number of teachers \\
\cline { 2 - 3 } & Dëshmorët e Lirisë & 43 teachers \\
\cline { 2 - 3 } & Emin Duraku & 59 teachers \\
\cline { 2 - 3 } & Kushtrimi i Lirisë & 44 teachers \\
\cline { 2 - 3 } & Mustafa Greblleshi & 29 teachers \\
\hline Vasil Shanto & 40 teachers \\
\hline Xhezmi Delli & 19 teachers \\
\hline
\end{tabular}

Source: Author

After determining a statistical population of $\mathrm{N}=234$, by means of a ready-made statistical formula (accesed from Checkmarket, n.d.) we were able to establish the number of questionnaires to be completed. Based on the formula, with a population of 234 , a margin of error of $5 \%$, and a confidence level of $95 \%$, the sample size equals 146 . Therefore, the number of teachers needed to answer the questionnaires was 146.

The sample was deliberately chosen to meet the two criteria which were:

1. the individual must be working as a teachers in 9-year schools in the city of Tirana,

2. the individual must have at least two years of work experience as a teacher.

\section{Measuring instrument}

A two-part survey instrument was used to conduct this study. A ready-made questionnaire was used as a measuring instrument. The attitude measurement instrument used in the survey was "School Principals' Attitudes toward Inclusion (SPATI)” (Bailey, 2004).

The first part of the questionnaire collects demographic information from teachers such as their gender, age, education, work experience, whether they have had prior experiences of working with disabled children and training they have received in the field of inclusive education. Respondents were asked to respond on a 5-point Likert type scale, which ranged from Strongly Disagree to Strongly Agree. Cronbach's alpha was used to estimate the questionnaire's internal consistency (reliability). The Reliability coefficient of the study was calculated to be 0.807 (Cronbach's alpha reliability coefficient).

\section{Findings}

The sample of this study was 146 teachers, of whom $30 \%$ were female and $70 \%$ male. Majority of the teachers belonged to the age group of 41-50 years old (41.1\%), held a university a degree $(73.3 \%)$ and had more than 20 years of teaching experience (28.8\%). 62.3\% of teachers have had the experience of working with a disabled student, while $57.5 \%$ of them have received training in the field of inclusive education.

\section{Attitudes of male and female teachers towards the inclusion of students with disabilities in regular school programs}

To be able to determine whether there exist any differences among male and female teachers when it comes to their attitudes towards the inclusion of students with disabilities in regular school programs, an Independent Samples T-Test was carried out using an SPSS program. 
Table 2: Independent Samples T-Test

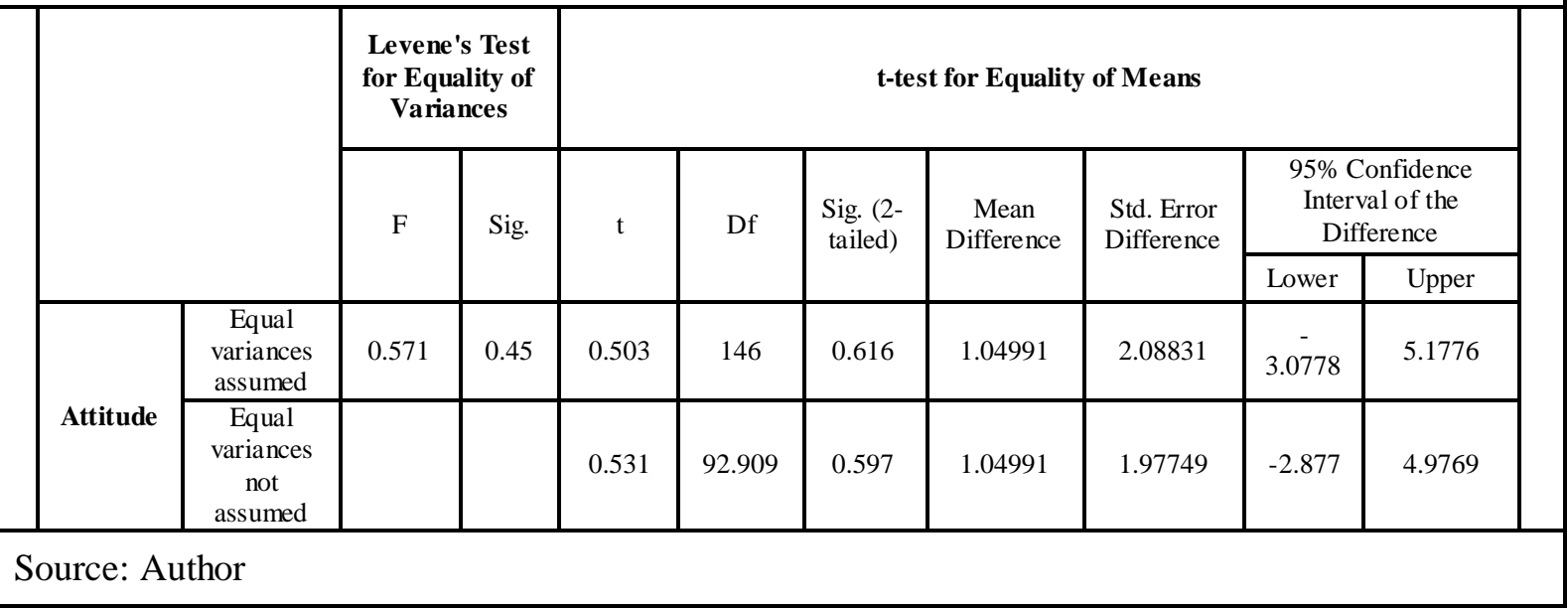

Based on the table above, it can be noticed that there are no significant changes in the attitudes of female and male teachers regarding the inclusion of children with disabilities in regular school programs, $\mathrm{t}(146)=0.503, \mathrm{P}=0.616$. Therefore, we conclude that there is hardly any connection between gender and respective attitudes towards inclusion of disabled children in regular schools.

\section{The relation between teachers' attitudes and training received in the area of inclusive education}

To find out whether there exists any connection between training received and teachers' attitudes towards inclusion of students with disabilities in regular school programs, the Pearson productmoment correlation coefficient was used.

Table 3: The relation between teachers' attitudes and training correlations

\begin{tabular}{|l|l|l|l|}
\hline & & Trainings & Attitude \\
\hline \multirow{4}{*}{ Trainings } & Pearson Correlation & 1 & 0.751 \\
\cline { 2 - 4 } & Sig. (2-tailed) & & 0.001 \\
\cline { 2 - 4 } & $\mathrm{N}$ & 146 & 146 \\
\hline \multirow{3}{*}{ Attitude } & Pearson Correlation & 0.751 & 1 \\
\cline { 2 - 4 } & Sig. (2-tailed) & 0.001 & 146 \\
\cline { 2 - 4 } & $\mathrm{N}$ & 146 & \\
\hline \multirow{2}{*}{ Source: Author } & \multicolumn{2}{|l}{} \\
\hline
\end{tabular}

Based on data obtained from the above table, it can be observed that there is a positive correlation between training received in the area of inclusive education and teachers' attitudes towards inclusion of students with disabilities in regular school programs, $r=0.75, n=146$ and $\mathrm{p}=0.001$.

\section{Discussion}

Our first hypothesis proposed that female teachers have more positive attitudes than male teachers when it came to the inclusion of students with disabilities in regular school programs. The proposition originated based on the assumption of gender roles, where women are considered by nature to be more caring. Results obtained through our study were similar to those found by Kala Parasuram in 2006 in India, who concluded that there is no correlation between teachers' gender and their attitudes towards inclusion of children with disabilities in regular school programs.

In Singapore, Thana Thaver, Levan Lim and Albert Liau (2014) have also investigated relations between gender and teachers' attitudes towards inclusion of students with disabilities in regular school programs. Findings from their study resemble those obtained through our study, while concluding that there are no distinctions in the attitudes of female and male teachers on the issue of inclusion of disabled children in regular school programs.

Our results also bear resemblance to Abdul Awal's study, which observed that gender does not influence a teachers' attitudes regarding the inclusion of students with disabilities in regular education. 
On the other hand Ahmmed, Sharma and Deppeler (2012), from the University of Monash, Australia, published in Journal of Research in Special Educational Needs a similar study to ours, however with opposite results. In their study they concluded that male teachers show less positive attitudes as compared to those shown by their female teachers. No arguments were proposed to justify the results obtained, while the authors recommended further research to investigate on the findings.

According to our second hypothesis, teachers who have received training in the area of inclusive education feel more positive towards disabled children than do those who have never received such training. Results from our study bolster this proposition.

Similar results have been obtained in other studies carried out by different researchers. Findings from Avramidis, Bayliss \& Burden (2000) point at the relationship between professional training in inclusive education and positive attitudes possessed by teachers who have received similar training in the inclusion of students with special needs in ordinary schools, thus reinforcing the idea that teachers specialized in inclusive education feel more positive towards this category of students than teachers who have not yet received training in the field.

According to Sharma and Chow (2008), teachers trained to work with students with learning behavior and emotional problems tend to have more positive attitudes toward integration. Similar findings are also reported in another study by Cambridge-Johnson, Hunter-Johnson and Newton (2014). Thaver, Lim and Liau (2014) have also concluded that teachers who had training in special needs and those with the most contact with people with disabilities displayed significantly more positive attitudes towards inclusive education than their counterparts who didnot.

Therefore, based on similar results in the studies above mentioned, training in inclusive education seems to affect significantly the attitudes of teachers towards the inclusion of students with disabilities in regular classes.

Teachers are principal actors who greatly influence the effectiveness of including students with special needs in regular school programs. Through proper training teachers can learn how to adapt school curricula to suit the special needs of disabled children. They can also learn how to make a class more attractive by introducing graphics, colors, and other such tools, aiming at a higher level of understanding among these students.

Through training, teachers learn how to manage students' behavior, which still proves to be problematic in Albania, as teachers have mostly received training merely informative in nature, rather than focusing on practical teaching methods.

Finally training can assist teachers in identifying and classifying disabilities, learn sign language to interact with students with hearing and speech impairments, and other tools for students with visual or learning impairments.

\section{Conclusion}

We are all responsible for education of people with disabilities, therefore, we concluded that teachers should be trained and should learn specific techniques to manage students' behavior. New methods of teaching as per the students' needs should be used, they should be trained to develop an individual plan for students, ways of managing bullying, ridicule or similar degrading and discriminating treatments against children with disabilities should be introduced. During the training of teachers, it would be good for teachers who have not previously been in contact, to be exposed to students with disabilities, in order to improve their attitudes toward students with disabilities and their integration in general classes. The implementation of law is important along with the establishment of assistant teachers in classes that have students with disabilities. The Ministry should provide rewards for teachers who have students with disabilities in their classrooms to further motivate them in their work. The development of cooperative relationships between psychologists and teachers, but also other professionals such as speech therapist should be encouraged. There should also be a development of cooperative relationships with parents and encourage them to participate in activities and decision making, and take the necessary responsibility in fulfilling the needs of disabled children. Finally, it is important that the children with disabilities feel welcome and safe in the school environment, and have complete access to everything school has to offer. 


\section{References}

Ahmmed, M., Sharma, U. \& Deppeler, J. (2012). "Variables affecting teachers' attitudes towards inclusive education in Bangladesh" Journal of Research in Special Educational Needs • Volume 12 • Number 3 • $2012132-1$.

Avramidis, E., Bayliss, P., \& Burden, R. (2000). "Student teachers' attitudes towards the inclusion of children with special educational needs in the ordinary school" Teaching and Teacher Education 16 (2000).

Bailey, J. (2004). "The validation of a scale to measure school principals' attitudes toward the inclusion of students with disabilities in regular schools" Australian Psychologist, March 2004; 39(1): 76 - 87 (Taylor \& Francis).

Cambridge-Johnson, J., Hunter-Johnson, Y., \& Newton, N. (2014). "Breaking the Silence of Mainstream Teachers' Attitude towards Inclusive Education in the Bahamas: High School Teachers' Perceptions" The Qualitative Report 2014 Volume 19 , Article 84, 1- 20. Retrieved from: http://www.nova.edu/ssss/QR/QR19/cambridgejohnson84.pdf

Checkmart (n.d.). Sample Size calculator. Market research resources. Retrieved from https://www.checkmarket.com/marketresearch-resources/sample-size-calculator/

Mittler. P. (1995). Special needs education an international perspective, British Journal of Special Education Vol.22, no.3, pp.105-8.

Salamanca Statement (1994): http://www.ecdgroup.com/docs/Salamanca_Statement_and_Framework_for _Action_on_Special_Needs_Education-16_05_2001-09_20_08.pdf

Sharma, U., \& Chow. E. (2008). "The Attitudes of Hong Kong Primary School Principals toward Integrated Education" Asia Pacific Education Review 2008, Vol. 9, No.3, 380-391. Retrieved from: http://files.eric.ed.gov/fulltext/EJ835209.pdf

Thaver, T., Lim, L., \& Liau, A. (2014). “Teacher variables as predictors of Singaporean pre-service teachers' attitudes toward inclusive education" European Journal of Research on Social Studies, Volume1, Issue 1, 1-8, June 2014. Retrieved from: http://iassr.org/rs/E010101.pdf 